a smaller effect on preserving nutritive value, but prevented sample alteration and a loss of nutritive value more so than transporting samples in a chilly-bin. This is likely due to liquid nitrogen rapidly reducing plan metabolic activity i.e. respiration and preserving macromolecular structures (Pelletier et al. 2010)

Freezer temperature had less impact on nutritive value than sample transportation or drying method, with little difference between storage at $-80^{\circ} \mathrm{C}$ or in a standard for freezer, except for NSC at $-80^{\circ} \mathrm{C}$ or in a stamples in freezer bettr proserved nutritive value attributes than storage in the chiller or at room temperature. Across all the post-sampling procedures, nutritive value preservation was poorest for chiller and room temperature stored samples. When comparing chiller stored samples to room temperature stored samples, the chiller best preserved nutritive attributes but results were inconsistent between years; and may reflect the difficulty in controlling these storage eniroments. Dale et al. (2016) compared storage of pasture samples in a fridge at $4^{\circ} \mathrm{C}$ versus ambient temperatures and concluded samples were best stored in a fridge and analysed within 24 hours of sampling.

Access to liquid nitrogen and a freeze-drier to obtain accurate estimates of nutritive value may be limited to those undertaking scientific research; an underestimat of nutritive value may therefore be inevitable for more basic sampling practices. However, it is often the relative nutitive values of forage samples that are required when ranking the nutive values of differ  or other forage species. If this is the case, consistency in post-harvest sampling method is important. Results from this study show that the different post-harvest sampling methods gave similar rankings for nutritive value in both years, demonstrating that the different methods can give consistent results. When a particular method is chosen, consistency in other factors, such as time of day of sampling, are also important and will enable nutritive value estimates to be more easily compared.

\section{Conclusions}

When transporting, storing and drying pasture samples post-harvest, the following is recommended:

- Snap-freeze and transport the samples in liquid nitrogen to the laboratory as quickly as possible; transporting samples in a chilly-bin will result in loss of nutritive value.

- In the laboratory, store the samples in a standard freezer $\left(-18^{\circ} \mathrm{C}\right)$ or in a $-80^{\circ} \mathrm{C}$ freezer, preferably no in a chiller or at room temperature.

- For an accurate estimate of nutritive value, the most important factor is to freeze-dry the pasture samples, oven-drying will result in a loss of nutritive value.
If there is no access to liquid nitrogen or a freezedrier, then consistency of post-sampling procedure is important, as is processing the samples as quickly as possible. For example, harvest the samples at the same time of day if sampling on different days. Avoid the samples being in transit, stored at room temperature, or in the fridge (chiller) for several days.

\section{ACKNOWLEDGEMENTS}

This study was funded by AgResearch SS1F A19054(C). We would like to thank NZ Agriseeds for permission to use the trial site, Robert Wieliczko for his freeze-drier expertise and Jim Crush and David Hume for helpful comments on the manuscript

\section{REFERENCES}

Alomar, D.; Fuchslocher, R.; De Pablo, M. 2003. Effect of preparation method on composition and NIR prectro al Feed Science and Technology 107: 191-200.

Corson, D.C.; Waghorn, G.C.; Ulyatt, M.J.; Lee, J. 1999. NIRS: Forage analysis and livestock feeding. Proceedings of the New Zealand Grassland Associations 61: 127-132.

Dale, A.J.; Gordon, A.W.; Archer, J.; Ferris C.P. 2016. Impact of sampling and storage technique, and duration of storage, on the composition of fresh grass when analysed using near-infrared fing near-infrarec reflectance spectroscopy. Grass and Forage Science. Deaville, E.R.; Flinn, P.C. 2000. Near-infrared (NIR) spectroscopy: an alternative approach for the estimation of forage quality and voluntary intake. pp. 301-320. In: Forage evaluation in ruminant nutrition. Eds. Givens, D.J.; Owen, E.; Axford, R.F.E.; Ohmed, H.M. CABI Publishing, Wallingford, UK.

Feedsmart 2. 2012. Feed sheep and cattle smarter workshop resource book. Beef + Lamb New Zealand and AgResearch.

Fulkerson, W.J.; Slack K.; Lowe K.F. 1994. Variation in the response of Lolium genotypes to defoliation. Australian Journal of Agricultural Research 45: 1309-1317.

GenStat for Windows. 2015. 18th Ed. VSN International Ltd., Hemel Hempstead, UK.

Kohn, R.A.; Allen, M.S. 1992. Storage of fresh and ensiled forages by freezing affects fibre and crude protein fractions. Journal of Science, Food and Agriculture 58: 215-220.

Pelletier, S.; Tremblay, G.F.; Bertrand, A.; Belenger, G.; Castonquay, Y.; Michaud R. 2010. Drying procedures affect non-structural carbohydrates and other nutritive value attributes in forage samples. Animal Feed Science and Technology 157: 139-150.

\title{
Implementing change: barriers and opportunities
}

T.A. NELSON ${ }^{1}$, M.A. BROWN ${ }^{2}$, S.J. FIELKE ${ }^{1}$, A.D. MACKAY ${ }^{2}$, P.R. PAYNE ${ }^{1}$, A.P. RHODES ${ }^{3}$ and W. SMITH ${ }^{1}$ AgResearch Ltd Ruakura, Private Bag 3123, Hamilton 3240, New Zealand ${ }^{2}$ AgResearch Ltd, Private Bag 11008, Palmerston North. New Zealand ${ }^{3}$ PGGWrightson Ltd, Barraud Street, Dannevirke 4930, New Zealand ${ }^{4}$ Private Consultant, 1016 Matheson Road, RD4, Waipawa 4274, New Zealand tracy.nelson@agresearch.co.nz

\section{Abstract}

Severe flooding and slips in the Manawatu-Whanganui region in 2004 resulted in the implementation of the voluntary Sustainable Land Use Initiative (SLUI), to support recovery and increase resilience. This paper identifies the barriers, opportunities and lessons for the implementation of Whole Farm Plans (WFPs). The research, conducted in 2016, involved interviews with 40 farm households. The findings demonstrate that the values and priorities of both SLUI and nonSLUI households were similar, highlighting the need to increase profitability, productivity and environmental protection. Both adopters and non-adopters express similar concerns about SLUI, including perceptions about its bureaucratic nature, cost and complexity. They differed to an extent when believing the SLUI aligns with their own values and goals. Non-signatories highlight their resistance to government intervention. They also feared the SLUI would thwart productivity and profits. There remains a need to more explicitly integrate social values and goals in any strategy to implement Whole Farm Plans.

Keywords: Sustainable Land Use Initiative, barriers, opportunity, values, environment, resilience

\section{Introduction}

The massive storm that hit New Zealand in February 2004 had its greatest impact on the ManawatuWhanganui region. The resultant floods constituted the largest emergency management event in New Zealand for 20 years, and the first major natural disaster to occur under new Civil Defence legislation (Ministry of Civil Defence and Emergency Management, 2004). The total cost of damage to agriculture alone was estimated at $\$ 180$ million, including stock losses; interuptions to milking; loss of pasture; damage to fences, plant and equipment; silting; and loss of feed and production. In hill country, 62000 individual landslides were recorded, covering 18000 ha. Twenty-nine thousand hectares were severely eroded (Horizons 2004; New Zealand Press Association 2004).

The major damage in hill country was slips. Erosion had major, negative impacts on water quality. In addition, downstream, large quantities of soil were deposited reducing the protection of infrastructure and farm land provided by stop-banks. An estimated 200 million tonnes of soil were lost.

The floods reprioritised erosion control on the local Council's agenda. In response, The Sustainable Land Use Initiative (SLUI) was designed and implemented. SLUt aimed to reduce erosion rates closer to The levels; build resilience in the rural sector and in the regional economy; protect lowland communities from the effects of upstream hill country erosion; and improve water quality (Horizons 2007).

The SLUI was introduced in 2005. Ten years later Horizons commissioned research to explore farmers' perspectives on how the SLUI contributed to sustainability and to identify any improvements that could be made to streamline delivery (Horizons 2016).

\section{Methods}

A core data set was developed through a series of in-depth, semi-structured interviews involving 20 hill country farmers who have signed-up to SLUI, and 20 who have not. In addition, all Field Officers employed by Horizons completed a questionnaire and subsequently met as a group with the authors to discuss their views.

Two priority areas, the Lower Rangitikei and Tiraumea, were identified as the study areas. Horizons generated a random list of farmers in each area. The questionnaires were field tested and where necessary revised. All interviews were conducted, face-to-face in May-July 2016. The design and data analysis of this qualitative social research was "triangulated" a process where two or more social science methods were used, in this case interviews and literate associated with WFPs, to test the strength of views expressed.

\section{Incentives and barriers}

Each farmer, after signing-up to SLUI, met the cost of farm plans and made a contribution towards the cost of environmental work (11/20). This bracketed ratio, here and elsewhere in the text, gives the number of responses over the total possible number of respondents. These numbers are not statistically valid, given the small 
sample size, but provide some indication of the weight iven by farmers to the issues and views expressed. This aligns with respondents' identification of farm accountants as encouraging adoption of SLUI, and confirms the views of private extension consultants an Horizons Field Officers, that for many farmers, SLUI is simply "good business" practice. Other key reason given by farmers for supporting the SLUI included the quality of the information provided, the need to respond to the impact of the 2004 floods, and tust in a Field Member). Fiend Offcers and extension (or Council

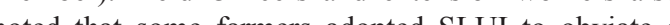
poted that some famers adopted SLUI to obviate a potential threat of compulsory environmental controls, or to present a positive image of their farm before sale. When SLUI and non-SLUI farmers were asked wha barriers they face in doing more environmental work (or doing that work quicker), all identified cost and (orme as the two domint constaints. Field Officers, confirm these explanations and noted age and health were additional (often related) factors. Some farmer also identified increasing age and a wish to reduce work load as an incentive, seeing SLUI as a vehicle to reduce effective farm area, and target efforts on priority areas.

In discussion with SLUI and non-SLUI farmers, costs and profits were repeatedly raised. No SLUI farmer identifed SLUT as having had a negative impa on profitability and some believed it has had a positive impact $(5 / 20)$. Most saw it as having no measurable impact on profitability, either positively or negatively. Farmers pointed out that implementing SLU required them to make a large financial contribution to environmental works, and some SLUI farmers $(12 / 20)$ noted additional, short to medium term costs for herbicide spraying to combat increased weed/scrub problems.

Farmers noted the difficulty in separating other management changes from the impact on profitability of the work completed under SLUI. Detailed productivity data obtained from six SLUI farmers showed increasing productivity per unit area and other trends in line with the industry as a whole: lower stocking rates, higher ewe liveweights, more lambs finished and more cattle trading.

Most SLUI farmers believed that any increase in profitability will only emerge in the longer-term. At the same time, they all valued their Farm Plan as a framework for changes in farm management. Increased farm productivity has undoubtedly filtered through and benefitted the local economy. Investment channelled through SLUI amounts to an annual average of almost $\$ 7000 /$ farm, a total investment of close to $\$ 140000$ for the 20 SLUI farmers in the study area. Ninety percent of this investment was spent locally by farmers, mainly on material supplies and labour. Perhaps most telling, however, was the $\$ 50$ million total spent on SLUI across the whole region (Todd 2015). Against the total cost of $\$ 350$ million dollars imposed as a result of the 2004 floods, this is a ratio of 1:7.

In practice, non-SLUI farmers interviewed were not easily distinguishable from SLUI signatories. The vast majority of non-adopters were happy to talk, aware of the environmental challenges on their property and the risks posed. Most wer actively pur property and the risks posed. Most were actively pursuing on-farm environmental work (18/20). They acknowledged the increased environmental resilience SLUI provided (11/20), its contribution to economic resilience (14/18) and believed it contributed to social resilience (10/18), although were less convinced of its contribution to sustainability at a regional level. The extent to which these perceptions of SLUI are in line with those of SLUI farmers was surprising. These similarities, however, some farmers' continued resistance to adoption.

In an attempt to gain a fuller insight on farmers' decision making, all the sample farmers (SLUI and non-SLUI) were asked to identify the beliefs and values they attach to their farm (Figure 1).

It was the similarities between the two groups which stood out. Nevertheless, of those farmers who have not signed-up, seventy-five percent (15/20) believe SLUI does not align with the beliefs or values they attach to their farm. Many believe SLUI would damage their financial returns or are uncertain as to its economic impact. The biggest difference was in terms of debt reduction and the lower emphasis non-SLUI farmers put on environmental sustainability. Discussion with both signatories and non-signatories suggests their respective attitudes were closely related to maintaining or improving their bottom line, and perceptions of the extent to which environmental concerns threaten the extent to which eniren of environmental risk and the timeframe within which each group views profitability (and risk). As a group, SLUI farmers take a longer-term perspective. They viewed resilience (and SLUI) as closely associated with good farming practice (including environmental management) rather than as an optional environmental tag-on. Yet of all those farmers interviewed who have chosen not to sign-on, 18 out of 20 could identify extensive to sign-on, 18 out of 20 could id have implemented on their farms sice 2004. The included tree planting on vulnerable slopes along waterways $(13 / 18)$ frequently combined with improved management of water courses (including drainage), fencing, the retirement of selected areas, and conservation, including the development of QEII Trusts. In most cases, the 2004 floods acted to expand environmental efforts. For some farmers,

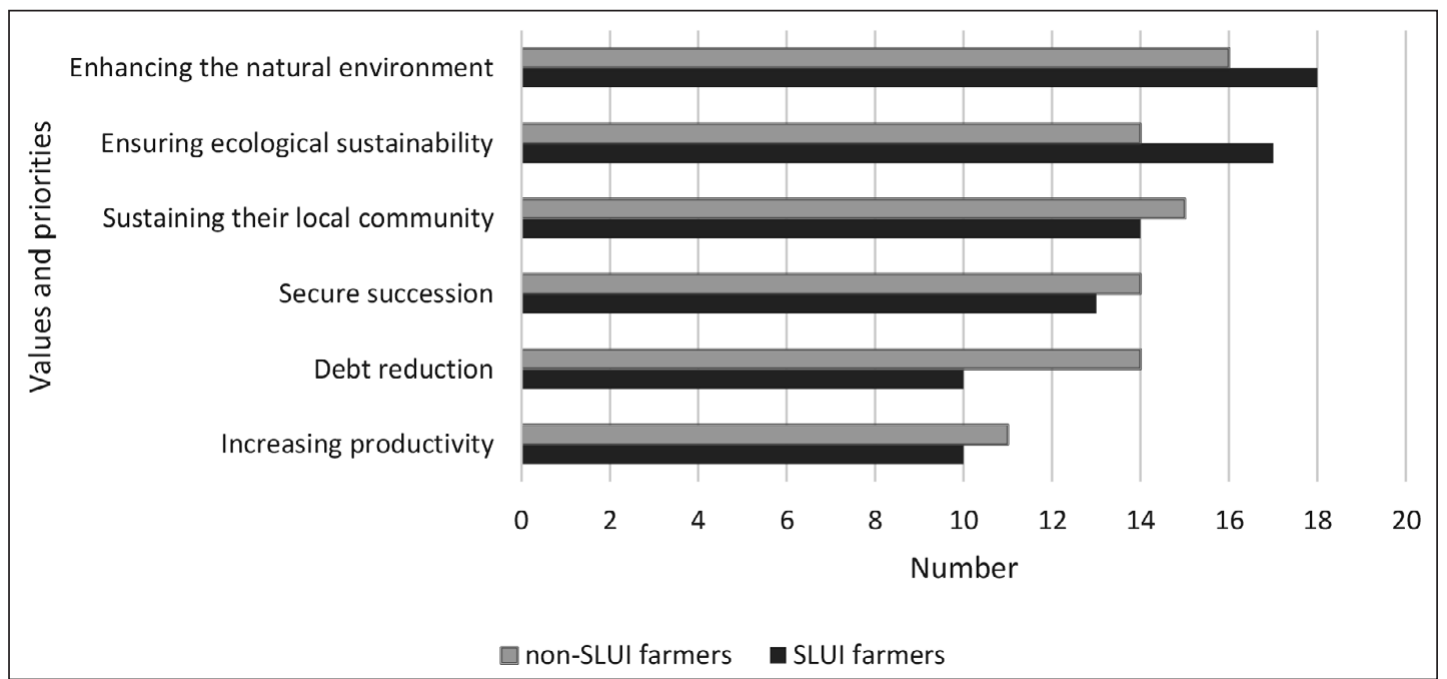

Figure 1 Values and priorities farmers attach to their farm.

SLUI represents no more than a continuance of earlier Conservation Board work

Importantly, non-SLUI signatories typically put a high value on personal space, and distrust any form of government intervention (SLUI is frequently seen as the "thin end of the wedge"). As one farm family explained, "It's our farm and our responsibility. We're independently minded". Other intervening factors identified included a "fear of being seen to be green", and for another, the view that all erosion is natural and human intervention for erosion control largely irrelevant. These are individual opinions, but highlight the importance of each farmer's self-image and values in their policy response.

Discussing specific concerns regarding SLUI, those farmers who have not signed-on perceived it as overly for money), and unduly complex. SLUI farmers express the same concerns. Some farmers associate environmental policies, such as SLUI, with the "bureaucrats" in their Regional Council However, when questioned in more detail, farmers' perceptions were more strongly focused on "excessive" paperwork and documentation, and embraced a distrust of all officials, scientists, and other outside "experts". These interpretations and explanations also tie-back to farmers' deeper attitudes, values and self-image. SLUI and non-SLUI farmers were logical and rational. They shared similar values and farm goals, but differed in the path they chose to follow.

\section{Discussion}

The Sustainable Land Use Initiative was, considering most criteria, a demonstrable success. Manderson et al. (2013) stated that after 7 years, the area managed under
SLUI was 295818 ha, in excess of the original target of $267300 \mathrm{ha}$. They also concluded that erosion rates had lowered to near natural levels, and that the rural sector was more resilient to future major storms, with lowland communities better protected against upstream erosion, and that water quality had increased. Todd (2015) argely confmed these findings, which again were paper, and the views expressed by farmers themselves. Given the productivity increases achieved an the flow of funds channelled through SLUI, farmers uncertainty as to any increase in the sustainability of their local communities might seem paradoxical. Certainly, respondents saw erosion control and flood prevention as increasing environmental sustainability well beyond the farm gate. They also accepted that, as the bulk of ef Studies of the 2004 floods, however, demonstrate that concepts of sustainability go well beyond conventional statistical measures. Farm households described the floods as a generating "coming together", demonstrated in the mutual aid and support they (the farmers) received. At the same time, the floods highlighted the vulnerability of farming communities as a consequence of loss of public facilities and services, including schools, police and other social services (Smith et al. 2011). Thus, while the inflow of investment associated with SLUI is undoubtedly positive and may have slowed population decline, it is unlikely on its own to address much wider concerns and needs.

The impact and consequences of the storm and floods of 2004 was fundamental to understanding the implementation of SLUI. What stands out in this 
instance, was the extent to which the policy momentum generated by the events of 2004 has been maintained for over a decade. Seventy-five percent of farmer interviewed who have not yet signed-up still expres interest in adopting the SLUI.

Both SLUI and non-SLUI farmers "buy-in" to the threat posed by farm erosion, while also acknowledging other environmental issues including weeds, pests, flooding, and pugging. Farmers are known to respond more positively to environmental policy initiatives based on practical, demonstrable evidence of value and success (Cary et al. 2001). This together with the empirical evidence presented above implies that for some farmers at least, an "information deficit" persists. This was confirmed by non-adopters identifying that they remain open to persuasion, subject to a number of information gaps being filled: more information and understanding more evidence that SLUI involves hip between Council and landowner (one that respects farmers goals and reflects an understanding of the farm); confirmation that property rights are observed; less paper work; greater flexibility in implementation of the plan (particularly with respect to the control retained over the management and farm use); and information that would address existing concerns about the financial implications of SLUI on farm business.

International research findings demonstrated that sustainable development involved the interdependence of environmental, economic, social, and institutional factors and the strengthening of these linkages that reduce vulnerability and increase resilience (UNEP 2013). Building resilience is not, as shown, necessarily or directly translatable into annual economic returns, nor easily identified in the potential market value of individual farms. The multi-dimensional nature of resilience is not necessarily explicitly recognised by farmers who, at least in the short-term, view SLUI as an environmental policy directly linked to erosion control and water management, and disconnected to business growth or wider social needs.

The success of SLUI is largely undisputed. There is substantial evidence of the potential to increase it uptake, but the context has changed. Further uptake might be accelerated by a more explicit recognition that SLUI is less of an environmental policy than a broad-based strategy to build sustainability in all its dimensions; recognising that this requires better reframing in terms of trust, respect, and wider busines and social goals inherent in farmers' own short-term and long-term management goals

\section{ACKNOWLEDGEMENTS}

any thanks to all the farmers who gave their time freely to discuss their experiences. Thanks also to the staff at Horizons Regional Council for their input into this work. This research was funded by the AgResearch Resilient Rural Communities project.

\section{REFERENCES}

Cary, J.; Webb, T.; Barr, N. 2001. The adoption of sustainable practices: some new insights: an analysis of drivers and constraints for the adoption of sustainable practices derived for research. (Reference Number BRR19) Land and Water Australia.

Horizons Regional Council. 2004. Storm: civil emergency - Storm and flood report, Palmerston North.

Horizons Regional Council. 2007. Application to Ministry of Agriculture and Forestry's Sustainable Land Management Fund (HCE), Unpublished. Palmerston North.

Horizons Regional Council. 2016. It's everybody's business: whole farm plans - a vehicle for implementing policy (A contract report by AgResearch Ltd). (https://www.horizons.govt.nz/ publications). Accessed 20 July, 2017.

Crises as catalysts for adaptation: human response to major floods. Research report (ESRC Environment and Human Behaviour New Opportunities Programme) Award No. RES-221-25-0037.

Manderson, A.; Mackay, A.; Lambie, J.; Roygard, J. 2013. Sustainable land use initiative by Horizons. New Zealand Journal of Forestry 57: 4-8.

Ministry of Civil Defence and Emergency Management. 2004. Review of the February 2004 flood event. Wellington. (www.civildefence.govt.nz publications)

New Zealand Press Association. 2004. Government boosts flood aid to $\$ 30$ million. New Zealand Herald, $4^{\text {th }}$ August.

Smith, W.; Davis-Colley, C.; Mackay, A.; Bankoff, G. 2011. The social impact of the 2004 Manawatu floods and the "hollowing out" of rural New Zealand. Disasters 35: 540-553.

Todd, M. 2015. SLUI Works Internal Audit Report. Unpublished contract report for Horizons Regional Council, Report 2015/INT/1515.

United Nations Environment Programme (UNEP). 2013. Embedding the Environment in Sustainable Development Goals. UNEP Post-2015 Discussion Paper 1,UNEP, Nairobi. (sdg.earthsystemgovernance. org/sgd/publications). Accessed 20 July, 2017.

\section{ACKNOWLEDGEMENTS}

The Editor thanks the following for their help in reviewing the papers published in this issue of the Journal of New Zealand Grasslands

Dave Barker
Denise Bewse

Alistair Black

Chris Boom

Rachael Bryant
Marie Casey

Marie Casey
David Chapman

Dave Clark

Tim Clough

Gerald Cosgrove

Lydia Cranston

Jim Crush

Robyn Dynes

Doug Edmeades

Han Eerens

Tom Fraser

Pip Gerard

Allan Gillingham
Travis Glare

Andrew Greor

Paul Guy

Kerry Harrington

Warwick Harris

Mike Hedley

Harold Henderson

David Hume

Kathryn Hutchinso

Glenn Judson

Geoff Kaine

Paul Kenyon

Graham Kerr
Greg Lambert

Stewart Ledgard

Warwick Lissaman

Ignacio Lopez
Michael Mackay

Sue Mason

Cory Matthew

Julia McCullough

Alister Metherell

Jim Moir

Ross Monaghan

Derrick Moot

Steve Morris

Jeff Morton

Zhongnan Nie

Reddy Pullanagari

Richard Rawnsley
John Rendel

Alvaro Romera

Val Snow

David Stevens

Alan Stewart

Mark Trotter

Armin Werner

Victoria Westbrooke

Keith Widdup

Bruce Willoughby

Cathal Wims 